\title{
The influence of animals from embryo transfer on the genetic evaluation of growth in Simmental beef cattle by using multi-trait models
}

\author{
Rodrigo Reis Mota ${ }^{1}$, Paulo Sávio Lopes ${ }^{1}$, Luiz Fernando Aarão Marques ${ }^{2}$, Luciano Pinheiro da Silva ${ }^{1}$, \\ Marcos Deon Vilela de Resende ${ }^{3,4}$ and Robledo de Almeida Torres ${ }^{1}$ \\ ${ }^{1}$ Departamento de Zootecnia, Universidade Federal de Viçosa, Viçosa, MG, Brazil. \\ ${ }^{2}$ Departamento de Zootecnia, Centro de Ciências Agrárias, Universidade Federal do Espírito Santo, Alegre, \\ ES, Brazil. \\ ${ }^{3}$ Embrapa Florestas, Colombo, PR, Brazil. \\ ${ }^{4}$ Departamento de Engenharia Florestal, Universidade Federal de Viçosa, Viçosa, MG, Brazil.
}

\begin{abstract}
The weight records from Simmental beef cattle were used in a genetic evaluation of growth with or without the inclusion of animals obtained by embryo transfer. A multi-trait model in which embryo transfer individuals were excluded (MTM1) contained 29,510 records from 10,659 animals, while another model without exclusion of these animals (MTM2) contained 62,895 weight records from 23,160 animals. The weight records were adjusted for ages of 100 , $205,365,450,550$ and 730 days. The (co)variance components and genetic parameters were estimated by the restricted maximum likelihood method. The (co)variance components were similar in both models, except for maternal permanent environment variance. Direct heritabilities $\left(\mathrm{h}_{\mathrm{d}}{ }_{\mathrm{d}}\right)$ in MTM1 were $0.04,0.11,0.20,0.27,0.31$ and 0.42 , while in MTM2 they were $0.11,0.11,0.17,0.21,0.22$ and 0.26 for 100, 205, 365, 450, 550 and 730 days of age, respectively. Estimates of $h^{2}{ }_{d}$ in MTM1 were higher than in MTM2 for the weight at 365 days of age. Genetic correlations between weights in both models ranged from moderate to high, suggesting that these traits may be determined mainly by the same genes. Animals from embryo transfer may be included in the genetic evaluation of Simmental beef cattle in Brazil; this inclusion may provide potential gains in accuracy and genetic gains by reducing the interval between generations.
\end{abstract}

Keywords: body weight, (co)variance components, heritability.

Received: May 30, 2012; Accepted: October 8, 2012.

\section{Introduction}

In beef cattle breeding, dams exert a greater influence on the phenotype of the progeny than sires. In addition to their genetic contribution, females contribute to the maternal environment of the progeny. The influence of maternal environment on animal phenotype is known as the maternal effect. Genetic differences among dams are expressed in their offspring through the maternal environmental contribution (Willham, 1963).

The efficacy of a breeding program depends on the accuracy of the genetic evaluation to which individuals are submitted. Consequently, there is a need to develop models that can provide more reliable genetic parameters in order to improve the classification of individuals and quantify their contribution to genetic gain. To obtain a more reliable estimate of (co)variance components and achieve better re-

Send correspondence to Rodrigo Reis Mota. Rua José Teotônio Pacheco 270/301, Clélia Bernardes, 36570-000 Viçosa, MG, Brazil. E-mail: rreismota@ hotmail.com. sponses to selection it is essential to consider the production and genealogy of females so that each effect (additive direct genetic effect, additive maternal genetic effect and maternal permanent environmental effect) can be properly estimated (Pires and Lopes, 2001).

The reproductive rate of beef cattle can be combined with the use of reproductive biotechnologies to accelerate genetic changes in herds (Bilhassi et al., 2010). Among the techniques available, embryo transfer (ET) has been used in cattle and, when coupled with artificial insemination and quantitative genetic techniques, allows large scale genetic gains in animal breeding programs. Selection becomes quicker and more accurate because of an increase in selection intensity and a decrease in the interval between generations due to several offspring per female (Costa and Silva, 2004). Based on simulated data, Souza (Souza GH, 2008, $\mathrm{PhD}$ thesis, Universidade Federal de Viçosa, Viçosa, MG, Brazil) reported that over a period of 42 years reproduction by traditional methods would result in only six generations 
whereas a breeding program that included animals obtained by ET would involve 14 generations.

However, the use of ET creates problems with the genetic evaluation of animals because it does not allow estimation of the maternal effects of the biological mother (additive genetic effects and permanent environment effect) since the offspring are raised by a foster dam rather than by the biological mother. The most common solution to this problem is to exclude animals produced by ET from the genetic evaluation of traits for which the maternal effect may be important. This is done because the maternal permanent environmental effect is provided by the foster dam rather than by the biological mother. Besides, in most cases, the offspring of a single biological mother are raised by different foster cows. However, the exclusion of these animals can reduce the accuracy of estimates of (co)variance components and genetic parameters and the prediction of breeding values.

An alternative to the foregoing approach would be to include the genealogy of the biological mother in the analysis of the additive maternal genetic effect (this would provide more accurate estimates of (co)variance components) and exclude the genealogy of the biological mother (to eliminate the maternal permanent environmental effect provided by foster dams that are usually not Simmental dams). To be possible the estimation of additive direct genetic and additive maternal genetic effects, this approach includes the foster dams as random effects in the model; however, these dams are included with no known genealogy and no relationship with animals in the solutions vector. In addition, each progeny is considered to originate from a different foster dam, i.e., even if a foster dam has more than one progeny each calf is considered as if the foster dams were different (Van Vleck, 1990).

In a study of Simmental beef cattle using multi-trait models for weight at 100 and 120 days, Bilhassi et al. (2010) noted that higher direct heritability values were obtained with models that included animals obtained by ET and concluded that the inclusion of these animals provided greater genetic gains in breeding programs. Since the inclusion of animals from ET may lead to greater genetic gains and since few studies have used this approach, the aim of this work was to employ multi-trait models to assess the effect of including animals obtained by ET on genetic evaluation in Simmental cattle.

\section{Material and Methods}

The database analyzed in this study consisted of the weights of Simmental beef cattle from 485 farms and was provided by the Brazilian Association of Simmental and Simbrasil Breeders (Associação Brasileira de Criadores das Raças Simental e Simbrasil - ABCRSS), located in the municipality of Cachoeiro de Itapemirim, ES, Brazil. Weight records from the $60^{\text {th }}$ to the $819^{\text {th }}$ days of age of animals born between 1974 and 2006 were used.
Two data files were prepared for the analysis using multi-trait models (MTM). In the first file (MTM1), animals produced by the ET technique were excluded whereas in the second file (MTM2) these individuals were included. The method proposed by Van Vleck (1990) was used in this analysis. This method includes the genealogy of the biological mother for estimation of the additive maternal genetic effect and the foster dams with no known genealogy and no relationship with animals present in the solutions vector, thus allowing assessment of the additive direct genetic and additive maternal genetic effect, as well as estimation of the maternal permanent environmental effect.

Calves from cows whose ages at calving were $<700$ and $>2340$ days were excluded from the analyses. The contemporary group defined by animals of the same sex, year, season (1 = January to March, $2=$ April to June, $3=$ July to September and $4=$ October to December) and farm of birth was considered as the fixed effect while the age classes (in days) of the cows at calving (class 1: 700-1,109; class 2: 1,110-1,519, class 3: 1,520-1,919 and class 4: 1,920-2,340) were considered as a covariate in the linear and quadratic effect. The additive direct genetic, additive maternal and maternal permanent environmental effects were considered as random effects. Contemporary groups with less than three observations were excluded from the analyses.

The data files used in this study consisted of weights adjusted for ages at 100 (W100), 205 (W205), 365 (W365), 450 (W450), 550 (W550) and 730 (W730) days old; these weights corresponded to values obtained from animals in the age intervals of $60-149,150-299,300-419,420-499$, 500-619 and 620-819 days old, respectively.

The weights were adjusted using the expression:

$$
\mathrm{AWi}=\mathrm{Wj}+[(\mathrm{Wi}-\mathrm{Wj}) /(\mathrm{Di})] \mathrm{x}(\mathrm{Ii})
$$

where $\mathrm{AWi}=$ weight adjusted for age $\mathrm{i}, \mathrm{Wi}=$ weight observed close to standard age $\mathrm{Ii}, \mathrm{Wj}=$ previous weight observed at weight $\mathrm{Di}, \mathrm{Ii}=$ standard age $[\mathrm{i}=1$ (100 days)... 6 (730 days) and $\mathrm{Di}=$ age (in days) of observation Wi.

Weight records outside the ranges defined by the average of the contemporary group (about three standard deviations) were excluded. After constraints, MTM1 consisted of 29,510 records from 10,659 animals (the progeny of 1,289 sires and 7,332 dams) and MTM2 consisted of 62,895 records from 23,160 animals (the progeny of 1,558 sires and 9,699 dams). Tables 1 and 2 summarize the descriptive statistics of files MTM1 and MTM2, respectively. Table 3 shows the structure of MTM1 and MTM2 in relation to the number of records per animal. The pedigree of the animals was renumbered using the program Renped developed by Silva (Silva FG, 2011, MSc thesis, Universidade Federal de Viçosa, Viçosa, MG, Brazil). The numerator relationship matrix used in the analyses contained 41,904 animals.

The organization of the data and consistency analysis were done using SAS (2004) software. Estimates of the 
Table 1 - Description of weights from file MTM1 pre-adjusted to 100 (W100), 205 (W205), 365 (W365), 450 (W450), 550 (W550) and 730 (W730) days old.

\begin{tabular}{lccccccccc}
\hline Weight & N & Sires & Dams & CG & Mean $(\mathrm{kg})$ & SD $(\mathrm{kg})$ & CV $(\%)$ & Min $(\mathrm{kg})$ & Max $(\mathrm{kg})$ \\
\hline W(100) & 6236 & 975 & 4606 & 1192 & 130.8 & 40.3 & 30.8 & 49.1 & 319.6 \\
W(205) & 7938 & 1119 & 5740 & 1389 & 222.6 & 60.4 & 27.1 & 88.8 & 446.7 \\
W(365) & 6070 & 961 & 4504 & 1208 & 338.5 & 83.8 & 24.8 & 156.6 & 639.6 \\
W(450) & 3666 & 738 & 3458 & 960 & 380.5 & 90.3 & 23.7 & 177.3 & 678.1 \\
W(550) & 3468 & 693 & 2790 & 902 & 441.1 & 104.5 & 23.7 & 196.5 & 793.2 \\
W(730) & 2132 & 505 & 1815 & 636 & 562.7 & 141.6 & 25.2 & 238.1 & 1108.5 \\
\hline
\end{tabular}

Table 2 - Description of weights from file MTM2 pre-adjusted to 100 (W100), 205 (W205), 365 (W365), 450 (W450), 550 (W550) and 730 (W730) days old.

\begin{tabular}{lccccccccc}
\hline Weight & $\mathrm{N}$ & Sires & Dams & CG & Mean $(\mathrm{kg})$ & SD $(\mathrm{kg})$ & CV $(\%)$ & Min $(\mathrm{kg})$ & Max $(\mathrm{kg})$ \\
\hline W(100) & 13102 & 1197 & 6247 & 2029 & 130.5 & 38.7 & 29.7 & 46.4 & 319.6 \\
W(205) & 16585 & 1352 & 7652 & 2380 & 224.1 & 57.6 & 25.7 & 83.7 & 454.2 \\
W(365) & 13090 & 1173 & 6155 & 2099 & 341.1 & 79.6 & 23.3 & 154.5 & 641.1 \\
W(450) & 7930 & 917 & 4260 & 1657 & 383.0 & 85.1 & 22.2 & 177.3 & 678.1 \\
W(550) & 7551 & 859 & 4037 & 1557 & 447.3 & 100.1 & 22.4 & 193.6 & 815.8 \\
W(730) & 4637 & 653 & 2746 & 1125 & 566.4 & 133.5 & 23.6 & 238.1 & 1108.5 \\
\hline
\end{tabular}

CG - contemporary groups; CV - coefficient of variation; Max - maximum value; Min - minimum value; $\mathrm{N}$ - number of observations; $\mathrm{SD}$ - standard deviation.

Table 3 - Number of records per animal in files MTM1 and MTM2.

\begin{tabular}{lccccc}
\hline & \multicolumn{2}{c}{ MTM1 } & & \multicolumn{2}{c}{ MTM2 } \\
\cline { 2 - 3 } \cline { 5 - 6 } Records & Number of animals & Percentage (\%) & & Number of animals & Percentage (\%) \\
\hline Total & 10659 & 100 & & 23160 & 100 \\
Animals with 1 record & 2915 & 27.35 & & 6473 & 27.95 \\
Animals with 2 records & 2401 & 22.53 & & 5433 & 23.46 \\
Animals with 3 records & 1938 & 18.18 & & 4352 & 18.79 \\
Animals with 4 records & 1624 & 15.23 & & 3243 & 14.00 \\
Animals with 5 records & 1203 & 11.29 & & 2426 & 10.48 \\
Animals with 6 records & 578 & 5.42 & & 1233 & 5.32 \\
\hline
\end{tabular}

(co)variance components were performed with the restricted maximum likelihood (REML) method (Patterson and Thompson, 1971) using WOMBAT software (Meyer, 2007). The convergence criterion was defined as the default setting of the software.

\section{Multi-trait model}

The traits were analyzed in pairs using two-trait analysis in which $n=p(p-1) / 2$, where $n$ is the number of analyses done and $\mathrm{p}$ is the number of traits (total of 15 combinations: W100-W205, W100-W365, W100-W450, W100-W550, W100-W730, W205-W365, W205-W450, W205-W550, W205-W730, W365-W450, W365-W550, W365-W730, W450-W550, W450-W730 and W550-
W730). This analysis provided estimates of the (co)variance components and genetic parameters.

The animal model, with six weight traits (weight at $100,205,365,450,550$ and 730 days of age), was described in matrix notation as follows:

$$
\mathrm{y}=\mathrm{X} \beta+\mathrm{Z}_{1} \mathrm{~d}+\mathrm{Z}_{2} \mathrm{~m}+\mathrm{Z}_{3} \mathrm{mp}+\mathrm{e}
$$

where $y=$ vector of observations, $\beta=$ vector of fixed effects, $d=$ vector of additive direct genetic random effects, $\mathrm{m}=$ vector of additive maternal genetic random effects, $\mathrm{mp}=$ vector of maternal permanent environmental random effects, $\mathrm{X}=$ incidence matrix for fixed effects, $\mathrm{Z}_{1}, \mathrm{Z}_{2}$ and $\mathrm{Z}_{3}=$ incidence matrices for additive direct genetic, additive maternal genetic and maternal permanent environmental 
random effects, respectively, and $\mathrm{e}=$ vector of residual random effects.

In using this model, the following assumptions were:

$$
\mathrm{E}\left[\begin{array}{c}
\mathrm{y} \\
\mathrm{d} \\
\mathrm{m} \\
\mathrm{mp} \\
\mathrm{e}
\end{array}\right]=\left[\begin{array}{c}
\mathrm{X} \beta \\
0 \\
0 \\
0 \\
0
\end{array}\right]=\mathrm{eV}\left[\begin{array}{c}
\mathrm{d} \\
\mathrm{m} \\
\mathrm{mp} \\
\mathrm{e}
\end{array}\right]=\left[\begin{array}{cccc}
\mathrm{A} \otimes \mathrm{G}_{\mathrm{d}} & 0 & 0 & 0 \\
0 & \mathrm{~A} \otimes \mathrm{G}_{\mathrm{d}} & 0 & 0 \\
0 & 0 & \mathrm{I}_{\mathrm{v}} \otimes \mathrm{Q} & 0 \\
0 & 0 & 0 & \mathrm{I}_{\mathrm{n}} \otimes \mathrm{R}
\end{array}\right]
$$

where $\mathrm{G}_{\mathrm{d}}=(\mathrm{co})$ variance matrix of additive direct genetic effects, $\mathrm{G}_{\mathrm{m}}=$ (co)variance matrix of additive maternal genetic random effects, $Q=($ co)variance matrix of maternal permanent environmental random effects, $\mathrm{R}=(\mathrm{co})$ variance matrix of residual random effects, $\mathrm{A}=$ numerator relationship matrix, $I_{V}=$ identity matrix whose order is the number of dams, $I_{n}=$ identity matrix whose order is the number of observations and $=$ Kronecker product operator.

The covariance between additive direct genetic and additive maternal genetic effects was assumed to be equal to zero.

\section{Results and Discussion}

Figure 1 shows that the direct genetic variances $\left(\sigma_{d}^{2}\right)$ for both models (MTM1 and MTM2) tended to increase during growth, although the estimates for MTM2 were generally lower than those for MTM1, i.e., the inclusion of animals originating from ET reduced the additive genetic variances. The estimates of additive genetic variances obtained here differed from those reported by Bilhassi et al. (2010) for this same breed of beef cattle.

The estimates of maternal genetic variances $\left(\sigma_{\mathrm{m}}^{2}\right)$ showed a similar behavior, except that the values for MTM2 were generally higher than those for MTM1 (Figure 1). These estimates increased up to 205 days of age then decreased from 205 to 365 days, with a new increase from 365 to 450 days and another drop from 450 to 550 days, followed by a marked increase in the last age interval, especially in MTM2. Increases in the estimates of $\sigma_{m}^{2}$ until weaning are expected since this period corresponds to the interval of greatest maternal influence. The behavior of maternal genetic variances observed here was similar to that reported by Menezes (Menezes GRO, 2010, PhD thesis, Universidade Federal de Viçosa, Viçosa, MG, Brazil) and Sousa Júnior et al. (2010) for Tabapuã beef cattle.

The behavior of maternal permanent environmental variances $\left(\sigma_{\mathrm{mp}}^{2}\right)$ in MTM1 and MTM2 diverged at various intervals along the growth curve (Figure 1). In MTM1, this variance increased progressively along the growth curve, whereas in MTM2 the variance increased up to 365 days and then dropped from 365 to 450 days, followed by a further increase from 450 to 550 days and a decline from 550 days. Bilhassi et al. (2010) also observed divergent behavior for the maternal permanent environmental variance in Simmental cattle. The difference in the behavior of $\sigma_{\text {mp }}^{2}$ be- tween MTM1 and MTM2 may be a reflection of variation in the average number of calves per cow at different age intervals in the same model. In MTM2, the average number of calves per cow was 2.3. At ages W450, W550 and W730, in which the maternal permanent environmental variance oscillated, this average was lower and may have influenced the estimates.

The estimates of residual variance $\left(\sigma_{\mathrm{e}}^{2}\right)$ increased with age, with no significant differences between MTM1 and MTM2. This lack of divergence may be a reflection of the decrease in the number of records at more advanced ages, leading to an increase in the residual and scale effect. Likewise, the phenotypic variance $\left(\sigma_{\mathrm{p}}^{2}\right)$ also increased almost linearly with age in both models. This finding agreed with the results of Marques et al. (1999), Baldi-Rey et al. (2010), Menezes (2010) and Boligon et al. (2010), who reported a similar linear behavior for other beef cattle breeds.

The direct heritabilities $\left(\mathrm{h}_{\mathrm{d}}^{2}\right)$ were of medium magnitude and similar in both groups, ranging from 0.04 to 0.42 in MTM1 and from 0.11 to 0.26 in MTM2. However, at older ages, the estimates were higher in model MTM1 compared to MTM2 (Table 4). These results were similar to those reported by Marques et al. (2000), who reported direct heritability values of $0.08,0.13,0.19$ and 0.24 at ages W100, W205, W365 and W550, respectively, in a model similar to MTM1, in this same cattle breed. The similarity in the values for MTM1 and MTM2 seen here may indicate that the inclusion of animals from ET allows congruent or even higher genetic gains in a breeding program, mainly by increasing the accuracy of selecting females and young animals.

The maternal heritability $\left(\mathrm{h}_{\mathrm{m}}^{2}\right)$ estimates were similar in the two models but tended to be low, with values ranging from zero to 0.06; Marques et al. (2000) also reported estimates of $\mathrm{h}_{\mathrm{m}}^{2}$ varying from zero to 0.05 in this same breed. However, in contrast to $\mathrm{h}_{\mathrm{d}}{ }_{\mathrm{d}}$, the estimates of $\mathrm{h}_{\mathrm{m}}{ }_{\mathrm{m}}$ for MTM1 were slightly lower than those for MTM2. The lower maternal heritability values for MTM1 may possibly be associated with higher direct heritability values because of differences in the partitioning of additive direct and additive maternal genetic variances for weights from 100 days until maturity.

The proportion of maternal permanent environment variances $\left(\mathrm{mp}^{2}\right)$ were similar in MTM1 and MTM2, indicating that although the foster dams had a different genetic composition there was no difference in the variation between the two groups. In a similar study, Bilhassi et al. (2010) reported approximate $\mathrm{mp}^{2}$ values for analyses with and without animals obtained by ET.

There were no differences in the estimates of residual variance $\left(\mathrm{ec}^{2}\right)$ as proportion of phenotypic variance, for MTM1 and MTM2. This finding indicates that animals obtained by ET can be included and that there may be gains in accuracy when appropriate methods are used. 

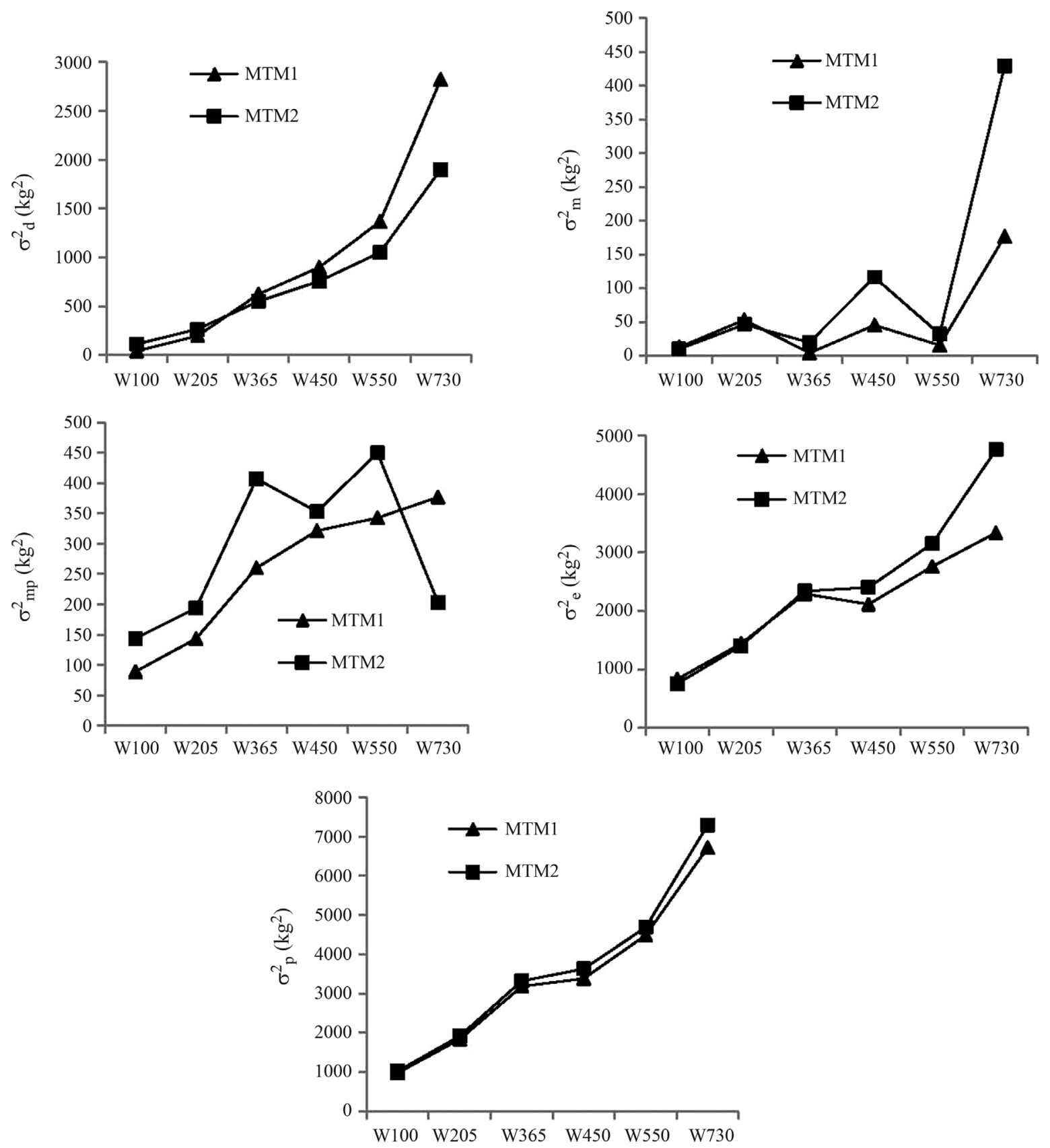

Figure 1 - Average estimates of additive direct genetic $\left(\sigma_{\mathrm{d}}^{2}\right)$, additive maternal genetic $\left(\sigma_{\mathrm{m}}^{2}\right)$, maternal permanent environmental $\left(\sigma_{\mathrm{mp}}^{2}\right)$, residual $\left(\sigma^{2} \mathrm{e}\right)$

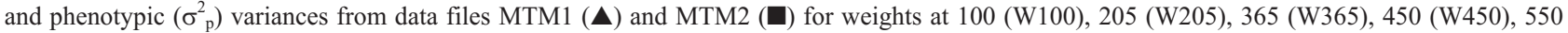
(W550) and 730 (W730) days old.

In the two models used here, the direct genetic correlations ranged from moderate to high, indicating that the traits are partly determined by the same genes and that selection for one of these traits will result in favorable responses for the others, i.e., genetic gains can be obtained at a given age by selection at another (Table 5). These results are similar to those reported by Dib et al. (2008) who reported values from 0.84 to 1.0 for several weights in Simmental beef cattle. In addition, the high correlation between weight at earlier ages and mature weight indicated that the selection of animals for greater weight at earlier ages would probably result in greater weight at maturity.

The residual correlations between MTM1 and MTM2 were similar but of lower magnitude when compared with additive direct genetic correlations. These values are coherent with those reported for Simmental beef cattle (Marques et al., 2000; Dib et al., 2008; Bilhassi et al., 2010).

Table 6 shows estimates of the maternal genetic and maternal permanent environmental correlations. Overall, maternal genetic correlations were high for MTM1 and me- 
Table 4 - Estimates of direct $\left(\mathrm{h}_{\mathrm{d}}^{2}\right)$ and maternal $\left(\mathrm{h}_{\mathrm{m}}^{2}\right)$ heritabilities and proportion of maternal permanent environmental $\left(\mathrm{mp}^{2}\right)$ and residual $\left(\mathrm{ec}^{2}\right)$ variances in relation to total phenotypic variance obtained from data files MTM1 and MTM2 (in parentheses) for weights at 100 (W100), 205 (W205), 365 (W365), 450 (W450), 550 (W550) and 730 (W730) days old.

\begin{tabular}{lcccc}
\hline Weight & $\mathrm{h}_{\mathrm{d}}^{2} \mathrm{a}^{\mathrm{a}}$ & $\mathrm{h}_{\mathrm{m}}^{2}{ }^{\mathrm{a}}$ & $\mathrm{mp}^{2 \mathrm{a}}$ & $\mathrm{ec}^{2 \mathrm{a}}$ \\
\hline W100 & $0.04(0.11)$ & $0.01(0.01)$ & $0.09(0.14)$ & $0.85(0.74)$ \\
W205 & $0.11(0.11)$ & $0.01(0.02)$ & $0.08(0.10)$ & $0.81(0.76)$ \\
W365 & $0.20(0.17)$ & $0.00(0.01)$ & $0.08(0.12)$ & $0.72(0.71)$ \\
W450 & $0.27(0.21)$ & $0.01(0.03)$ & $0.10(0.10)$ & $0.62(0.66)$ \\
W550 & $0.31(0.22)$ & $0.00(0.01)$ & $0.08(0.10)$ & $0.61(0.67)$ \\
W730 & $0.42(0.26)$ & $0.03(0.06)$ & $0.06(0.03)$ & $0.50(0.65)$ \\
\hline
\end{tabular}

${ }^{a}$ Average of two-trait analyses for MTM1 and MTM2 (in parentheses).

dium to high for MTM2. However, these correlations diverged considerably at certain ages, in which negative estimates were observed for MTM1. These results differ from those reported by Menezes (2010), who obtained high positive correlations in Tabapuã beef cattle. In contrast, the estimates of maternal permanent environmental correlations were positive, except for that between $\mathrm{W} 100$ and W730 (-0.16) in MTM2; the values in this model were moderate to high and were slightly higher in MTM1 (Table 6). Medium to high values indicate that the environmental effects promoted by the dam during the pre-weaning phase are of fundamental importance throughout the life of the animal. This finding reinforces the need for cows with a
Table 7 - Estimates of phenotypic correlations obtained from files MTM1 (above the diagonal) and MTM2 (below the diagonal) for weights at 100 (W100), 205 (W205), 365 (W365), 450 (W450), 550 (W550) and 730 (W730) days old.

\begin{tabular}{ccccccc}
\hline Weight & W100 & W205 & W365 & W450 & W550 & W730 \\
\hline W100 & - & 0.69 & 0.34 & 0.42 & 0.30 & 0.19 \\
W205 & 0.69 & - & 0.53 & 0.53 & 0.46 & 0.4 \\
W365 & 0.37 & 0.57 & - & 0.91 & 0.81 & 0.61 \\
W450 & 0.44 & 0.56 & 0.92 & - & 0.91 & 0.74 \\
W550 & 0.33 & 0.51 & 0.81 & 0.92 & - & 0.81 \\
W730 & 0.27 & 0.44 & 0.64 & 0.76 & 0.81 & - \\
\hline
\end{tabular}

good maternal ability to ensure the success of breeding programs in beef cattle (Menezes, 2010).

The phenotypic correlations estimated among ages W100, W205, W365, W450, W550 and W730 in MTM1 and MTM2 were of medium magnitude and higher at closer ages (Table 7). These findings were similar to those reported by Marques et al. (2000), who reported phenotypic correlations from 0.31 to 0.74 .

\section{Conclusions}

The influence of including animals obtained by the ET technique in genetic evaluations can be assessed using multi-trait models. In the case of Simmental beef cattle, the inclusion of such animals can lead to gains in the accuracy, as well as greater genetic gains, because of the decrease in the interval between generations.

Table 5 - Estimates of direct genetic (above the diagonal) and residual (below the diagonal) correlations obtained from files MTM1 and MTM2 (in parentheses) for weights at 100 (W100), 205 (W205), 365 (W365), 450 (W450), 550 (W550) and 730 (W730) days old.

\begin{tabular}{lcccccc}
\hline Weight & W100 & W205 & W365 & W450 & W550 & W730 \\
\hline W100 & - & $0.99(0.82)$ & $0.92(0.69)$ & $0.66(0.59)$ & $1.00(0.75)$ & $0.82(0.71)$ \\
W205 & $0.63(0.66)$ & - & $0.99(0.92)$ & $1.00(0.86)$ & $0.96(0.87)$ & $1.00(0.76)$ \\
W365 & $0.21(0.29)$ & $0.41(0.49)$ & - & $0.94(0.98)$ & $0.93(0.95)$ & $0.83(0.80)$ \\
W450 & $0.35(0.39)$ & $0.39(0.47)$ & $0.90(0.90)$ & - & $0.98(0.97)$ & $0.92(0.88)$ \\
W550 & $0.16(0.29)$ & $0.32(0.41)$ & $0.76(0.77)$ & $0.87(0.89)$ & - & $1.00(0.95)$ \\
W730 & $0.06(0.18)$ & $0.24(0.35)$ & $0.53(0.59)$ & $0.65(0.72)$ & $0.62(0.74)$ & - \\
\hline
\end{tabular}

Table 6 - Estimates of maternal (above the diagonal) and maternal permanent environmental (below the diagonal) genetic correlations obtained from files MTM1 and MTM2 (in parentheses) for weight at 100 (W100), 205 (W205), 365 (W365), 450 (W450), 550 (W550) and 730 (W730) days old.

\begin{tabular}{lcccccc}
\hline Weight & W100 & W205 & W365 & W450 & W550 & W730 \\
\hline W100 & - & $1.00(1.00)$ & $1.00(1.00)$ & $1.00(1.00)$ & $-1.00(0.48)$ & $-1.00(0.96)$ \\
W205 & $1.00(0.75)$ & - & $-1.00(1.00)$ & $-0.19(0.69)$ & $-1.00(0.64)$ & $-0.96(0.65)$ \\
W365 & $0.88(0.44)$ & $0.89(0.57)$ & - & $0.08(1.00)$ & $1.00(1.00)$ & $-1.00(0.99)$ \\
W450 & $0.69(0.54)$ & $0.67(0.96)$ & $1.00(0.97)$ & - & $1.00(1.00)$ & $-1.00(0.79)$ \\
W550 & $0.82(0.46)$ & $1.00(0.53)$ & $0.85(0.86)$ & $1.00(0.98)$ & - & $0.99(0.40)$ \\
W730 & $1.00(-0.16)$ & $1.00(0.54)$ & $1.00(0.97)$ & $1.00(1.00)$ & $1.00(1.00)$ & - \\
\hline
\end{tabular}




\section{Acknowledgments}

The authors thank the Associação Brasileira de Criadores das Raças Simental e Simbrasil (Brazilian Association of Simbrasil and Simmental Cattle Breeders ABCRSS) for providing the data used in this work.

\section{References}

Baldi-Rey FS, Alencar MM and Albuquerque LG (2010) Estimativas de parâmetros genéticos para características de crescimento em bovinos da raça Canchim utilizando modelos de dimensão finita. Braz J Anim Sci 39:2409-2417 (Abstract in English).

Bilhassi TB, Araújo Neto FR, Diaz IDP, Pessoa MC, Oliveira HN and Marques LFA (2010) Efeito da inclusão de animais provindos de transferência de embriões na avaliação genética de medidas ponderais na raça Simental. Proceedings of the 8th Simpósio da Sociedade Brasileira de Melhoramento Animal, Maringá, PR (Abstract in English).

Boligon AA, Mercadante MEZ, Forni S, Lôbo RB and Albuquerque LG (2010) Covariance functions for body weight from birth to maturity in Nellore cows. J Anim Sci 88:849-859.

Costa PA and Silva FM (2004) Segurança sanitária em transferência de embriões: Revisão bibliográfia. Rev Bras Reprod Anim 28:253-258.

Dib MG, Araújo Neto FR, Marques LFA, Figueiredo LGG, Curi RA and Oliveira HN (2008) Inferência Bayesiana na estimação de parâmetros genéticos e componentes de (co)variância para características de desenvolvimento ponderal da raça Simental. Proceedings of the 7th Simpósio da Sociedade Brasileira de Melhoramento Animal, São Carlos, SP (Abstract in English).
Marques LFA, Pereira JCC, Oliveira HN, Pereira CS and Bergmann JAG (1999) Componentes de (co)variância e parâmetros genéticos de características de crescimento da raça Simental no Brasil. Arq Bras Med Vet Zoot 51:363-370 (Abstract in English).

Marques LFA, Pereira JCC, Oliveira HN, Silva MA and Bergmann JAG (2000) Análise de característica de crescimento da raça Simental. Arq Bras Med Vet Zoot 52:527-533 (Abstract in English).

Meyer K (2007) WOMBAT - A tool for mixed model analyses in quantitative genetics by restricted maximum likelihood (REML). J Zhejiang Univ Sci B 8:815-821.

Patterson HD and Thompson R (1971) Recovery of inter-block information when block sizes are unequal. Biometrics 58:545-554.

Pires AV and Lopes PS (2001) Efeito materno em suínos. Rev Ceres 48:115-125 (Abstract in English).

SAS (2004) Statistical Analysis Software. SAS Institute Inc., Cary, NC.

Sousa Júnior SCS, Oliveira SMP, Albuquerque LG, Boligon AA and Martins Filho R (2010) Estimação de funções de covariância para características de crescimento da raça Tabapuã utilizando modelos de regressão aleatória. Braz J Anim Sci 39:1037-1045 (Abstract in English).

Van Vleck LD (1990) Alternative animal models with maternal effects and foster dams. J Anim Sci 68:4026-4038.

Willham LR (1963) The covariance between relatives for characters composed of components contributed by related individuals. Biometrics 19:18-27.

Associate Editor: Bertram Brenig

License information: This is an open-access article distributed under the terms of the Creative Commons Attribution License, which permits unrestricted use, distribution, and reproduction in any medium, provided the original work is properly cited. 